\title{
SAÚDE INTERNACIONAL: ALGUNS ASPECTOS CONCEITUAIS CONTEMPORÂNEOS
}

\author{
Tereza Cristina Scatena Villa ${ }^{1}$ \\ Teresinha Heck Weiller ${ }^{2}$ \\ Pedro Fredemir Palha ${ }^{3}$ \\ Silvana Martins Mishima ${ }^{4}$ \\ Emília Luigia Saporiti Angerami \\ Lenilde Duarte de Sá6
}

Villa TCS, Weiller TH, Palha PF, Mishima SM, Angerami ELS, Sá LD. Saúde internacional: alguns aspectos conceituais contemporâneos. Rev Latino-am Enfermagem 2001 maio; 9(3):101-5.

Este ensaio consiste em uma reflexão teórica acerca de algumas abordagens contemporâneas de Saúde Internacional, que suscitam o apontamento de questões que merecem ser refletidas e discutidas, permitindo subsidiar a compreensão no campo da Saúde Internacional em seus aspectos conceituais e operacionais, no processo de integração econômico-social das regiões de fronteira.

UNITERMOS: saúde para todos no ano 2000

\section{INTERNATIONAL HEALTH: SOME CONCEPTUAL CONTEMPORARY ASPECTS}

This study is a theoretical approach on international health with the purpose to point out some aspects which can enhance the understanding of the International Health field and its operational and conceptual elements in the socio-economic process of integration of neighboring countries.

KEY WORDS: health for all in the year 2000

\section{SALUD INTERNACIONAL: ALGUNOS ASPECTOS CONCEPTUALES CONTEMPORÁNEOS}

Este ensayo consiste en una reflexión teórica a cerca de algunos abordajes contemporáneos de salud internacional, permitiendo suscitan preguntas que merecen ser reflexionadas y discutidas, para posibilitar la comprensión en el campo de la salud internacional en sus aspectos conceptuales y operacionales, en el proceso de integración socioeconómica de los municipios de frontera.

TÉRMINOS CLAVES: salud para todos en el año 2000

\footnotetext{
${ }^{1}$ Enfermeira, Professor Associado; ${ }^{3} e^{4}$ Enfermeiro, Professor Doutor; ${ }^{5}$ Enfermeira, Professor Titular. Escola de Enfermagem de Ribeirão Preto da Universidade de São Paulo, Centro Colaborador da OMS para o desenvolvimento da pesquisa em Enfermagem. E-mail: tite@eerp.usp.br

${ }^{2}$ Enfermeira, Professor da Escola de Enfermagem da Universidade de ljuí - UNIJUÍ. Mestre em Enfermagem de Saúde Pública

${ }^{6}$ Enfermeira, Professor Doutor da Escola de Enfermagem da Universidade Federal da Paraíba
} 


\section{INTRODUÇÃO}

objetivo do presente ensaio é refletir sobre alguns aspectos das abordagens contemporâneas de Saúde Internacional tomando como fio condutor as tendências analisadas ${ }^{(1)}$, bem como situar a dimensão internacional de saúde no processo de integração econômico-social dos municípios de fronteira.

Consideramos também estudos desenvolvidos por outros autores com diferentes abordagens sobre o tema, que possibilitaram subsidiar a compreensão da saúde internacional, em seus aspectos conceituais e operacionais, presente nos serviços de saúde de municípios da fronteira do Brasil com a Argentina, tendo como referencial o processo de integração econômica do MERCOSUL (Mercado Comum do Cone Sul) na dimensão internacional de saúde.

Estudar a dimensão internacional dos serviços de saúde em municípios da fronteira decorre de inquietações referentes às relações que esses municípios estabelecem com a Argentina, Uruguai, Paraguai (países que compõem de fato o Mercosul) no campo da saúde, uma vez que se encontram no centro geográfico do processo de integração econômico, o MERCOSUL. Este por sua vez, trará implicações não só do ponto de vista das relações econômicas, mas produzirá, sem dúvida, modificações no campo social e cultural até então presentes junto às populações fronteiriças.

Ainda que o MERCOSUL estabeleça uma nova lógica de relações econômicas entre os países que o compõem, com profundos e talvez graves reflexos no campo social, é nas áreas de fronteiras que essas alterações tendem ser mais visíveis. Nesse sentido, todo conhecimento sobre a zona de fronteira meridional do Brasil, a qual constitui-se palco das transformações que irão operar na configuração sócio-espacial, que fazem parte do processo de integração, revestese de particular importância ${ }^{(2)}$. No campo da saúde, estudar esses espaços contribuirá para pensar novas estratégias de atenção às populações que aí vivem.

No contexto do processo de integração, a saúde não foi objeto de discussão entre os países signatários. Este tema não tem sido diferenciado das demais áreas, na medida em que bens e serviços tem sido tratados da mesma forma. Assim, a ação dos Estados signatários é imperiosa no estabelecimento de políticas de cooperação, tendo em vista o aumento de fluxo de pessoas, bens e serviços, fundamentos de um processo de integração ${ }^{(3)}$.

Estudar a fronteira não é mais possível na perspectiva de limite entre nações, e sim tendo a percepção de que a mesma incorpora um caráter contraditório, que ao mesmo tempo que separa, aproxima, visão essa fundamental em um contexto de integração. A oportunidade de estudar os serviços de saúde na relação de fronteira associa-se ao que hoje conhecemos como espaço fronteiriço: "seria o resultado das tensões e contradições multi-escalares existentes dentro da própria realidade loco-regional e o exercício da soberania dos Estados nacionais, profundamente permeados pelo sistema econômico e pelas redes de informações técnico-científicas" ${ }^{(4)}$.

A fronteira, nesse momento, deixa de ser o limite, o espaço das diferenças, dos serviços, do contrabando. Torna-se porosa, aberta para aproximações principalmente no campo das políticas sociais ${ }^{(5)}$.

0 campo da saúde internacional relaciona-se com a especificidade dos municípios de fronteira, ao considerar que a dimensão internacional da saúde decorre de determinações de ordem histórica, social, cultural, econômica e política entre as diferentes populações, transcendendo as políticas e fronteiras nacionais.

Os conceitos apresentados ${ }^{(2-5)}$ apontam algumas tendências contemporâneas sobre o conceito de Saúde Internacional que podem ser tomados como referência para os formuladores de política de Saúde Internacional nos países que compõem o MERCOSUL.

\section{A DIMENSÃO INTERNACIONAL DA SAÚDE}

\section{A Constituição das Organizações Internacionais de Saúde}

A Saúde Internacional é um tema relativamente novo em trabalhos na área de saúde e vem progressivamente ampliando-se, em decorrência do aumento natural de sua complexidade e das imbricações com outros setores, assim como das repercussões, na área da saúde, do crescimento acentuado da interdependência entre os países ${ }^{(6)}$.

Entretanto, as preocupações e controvérsias relativas à origem e à transmissão das doenças infecciosas, que tiveram e ainda têm repercussões no perfil epidemiológico dos países, datam de séculos passados. Com o advento do processo de colonização, os homens passaram a ter contatos com regiões, pessoas e produtos nos mais diferentes pontos do planeta exigindo, dessa forma, mecanismos eficientes para evitar possíveis contaminações, principalmente de doenças desconhecidas pelos países dominantes.

No século XX o aumento do comércio entre as nações, a melhoria e ampliação dos transportes e a diminuição das distâncias, determinaram modificações nas condições sanitárias em diferentes partes do planeta as quais não mais poderiam ser tratadas com indiferença ${ }^{(7)}$.

Ações significativas, no entanto, ocorreram para controlar as doenças na esfera internacional, no início do século XIX. Em 1833, no Egito, foi criado um Conselho Sanitário com representantes de vários países. 0 objetivo desse Conselho era de proteger os países 
europeus, cuidar de problemas de quarentena e de higiene internacional. Em 1839, realizou-se em Constantinopla, sede do governo turco, um encontro entre o Comitê de Saúde turco e representantes das forças estrangeiras, o qual buscava estabelecer acordo com relação ao sistema de quarentena. A primeira Conferência Internacional de Saúde realizou-se em 1851, produzindo resultados significativos, uma vez que possibilitou a convenção de uma série de normas na busca de um código sanitário internacional referente à quarentena, à notificação do cólera, da peste e da febre amarela. Também resultaram desse evento medidas legais no sentido da não interferência nas soberanias dos países ${ }^{(5)}$.

A cooperação sanitária internacional em saúde "nasce da compreensão cada vez maior de que, em um mundo que por mais de cem anos vem diminuindo de tamanho em virtude de uma interdependência econômica e política internacional cada vez mais complexa - a presença de doenças em uma área se constituía em perigo contínuo para muitos outros"(5).

Foi sob essa perspectiva que, em 1902, criou-se o escritório da $O P A S^{(8)}$ - Organização PanAmericana de Saúde, sede do escritório regional da OMS para as Américas e organismo do sistema inter-americano especializado em saúde. As atribuições da OPAS são similares àquelas da OMS. Composta de 38 governos membros, colabora com ministérios da saúde, instituições públicas e entidades privadas de seguridade social, universidades, ONGs e grupos comunitários dos países da região, além de cooperar com agências multilaterais, bilaterais e instituições financeiras internacionais em distintos setores relacionados com o tema da saúde ${ }^{(6)}$.

Em 1906, em Roma, foi instituído o Office Internacional d'Higiène Publique. Essa instituição passou a ser a primeira de caráter internacional, com função de reunir e distribuir informações epidemiológicas, principalmente em relação a peste, cólera, varíola, tifo exantemático e febre amarela. Em 1923 foi criada a Organização de Saúde da Liga das Nações, a qual tinha no serviço de inteligência epidemiológica uma de suas ações mais importantes. A Fundação Rockefeller, criada em 1909, foi uma entidade que ao longo da primeira metade do século XX, teve papel importante nas questões internacionais de saúde, fundamentalmente pelo fato desta financiar projetos para capacitação de recursos humanos, implementação e implantação de programas de saúde em quase todos os países do terceiro mundo ${ }^{(7)}$.

A Organização Mundial da Saúde-OMS, foi criada em 1946 após a segunda guerra mundial. Constitui-se na instituição de saúde internacional contínua mais antiga, passou a ter um papel atuante junto aos países nas relações internacionais e na diplomacia.

Nas últimas décadas, verifica-se que os Bancos Internacionais têm atuado de forma significativa nos países de Terceiro
Mundo em resposta às concepções atuais de desenvolvimento e ao consenso que se vem consolidando entre governantes e formuladores de políticas públicas a respeito da importância de serem destinados recursos para as áreas sociais, sobretudo para os setores de saúde e educação, como condição para reduzir-se a pobreza e, assim, assegurar a sustentabilidade do processo de desenvolvimento ${ }^{(6)}$.

Situam-se nesse universo, o Banco Mundial (BM), o Banco Interamericano de Desenvolvimento (BID), e o Fundo Monetário Internacional (FMI). Essas instituições que negociam e renegociam as dívidas externas da maioria dos países subdesenvolvidos, ou em desenvolvimento, passam a ser hoje, sem dúvida, as determinadoras das prioridades de investimentos no campo da saúde. Apostam alto no financiamento da rede hospitalar em toda América Latina, talvez por entenderem que esse é um investimento altamente rentável.

\section{Abordagens Contemporâneas de Saúde Internacional}

0 conceito de Saúde Internacional passou ao longo desse século por modificações significativas, as quais são decorrentes, ao nosso ver, da evolução do próprio conceito de saúde.

"Saúde Internacional é resultante da dinâmica social, cultural, econômica e da política internacional entre diferentes populações. Em função disso, saúde internacional deve ser considerada como parte das Relações Exteriores em que saúde e doença produzem repercussões que transcendem políticas nacionais e fronteiras nacionais" ${ }^{(1)}$.

Em 1991 por ocasião do estudo do caso do cólera no Peru, foram revisadas e analisadas ${ }^{(1)}$ quatro tendências básicas no campo da Saúde Internacional, as quais perpassam a compreensão das diferentes instituições que atuam no campo da saúde internacional. A primeira corrente defende o pressuposto que os Germes Não Respeitam Fronteiras, argumentando que, cada vez mais, as doenças infecciosas e outros perigos, tal como poluição ambiental, desafiam as fronteiras nacionais. Utiliza-se, principalmente, dos instrumentos de análise da saúde pública tradicional, cuja visão é unidimensional, biomédica, apolítica, ignorando a importância de negociação e cooperação regional. A literatura sobre saúde internacional propõe controlar e prevenir os focos e ameaças de perigos à saúde com uma abordagem que ultrapassa as fronteiras. Todavia, esses argumentos são insuficientes para o autor, pois não se considera as diferenças sociais, econômicas, e os problemas políticos relacionados à transmissão ou prevenção dos perigos à saúde que cruzam as fronteiras.

Muitos partidários dessa corrente encaram a população mundial de uma forma simbólica, percebida como uma entidade pouco expressiva no globo, e defendem a necessidade de políticas de saúde nas fronteiras nacionais apenas para controlar agentes 
patogênicos. São partidários da cooperação internacional, e consideram importantes os fatores sócio-econômicos; no entanto, os esforços de saúde internacional são negociados independentes da política econômica. Os que advogam essa corrente possuem uma visão de saúde internacional como entidade abstrata ou idealizada, quase independente do domínio nacional.

Esta abordagem descarta conflitos e diferenças de poder entre os países que interagem. As visões, usualmente percebidas no campo da saúde internacional para os países do terceiro mundo, passam pela redução dos problemas de superpopulação, de saneamento, de desnutrição, de doenças infecciosas dentre outras. Nessa perspectiva, predominou The Germs Disrespect Borders Concept durante o período de 1830 à 1924, anterior à criação das primeiras organizações internacionais de saúde ${ }^{(1)}$.

A segunda corrente parte do pressuposto de que Saúde Internacional é Saúde Para os Pobres.

Essa corrente aproxima-se da abordagem anterior, na medida em que as atividades de Saúde Internacional são de domínio unidimensional de saúde pública com uma visão biomédica. A unidimensionalidade decorre da visão apolítica e reducionista centrada na pobreza, e dirigidas aos pobres de países subdesenvolvidos. É usada ainda como instrumento oculto de política externa por agências bilaterais.

Os defensores dessa corrente advogam que Saúde Internacional refere-se especialmente aos problemas de saúde do mundo subdesenvolvido, reconhecendo a potencialidade, entendida como risco, da transmissão de doenças do Terceiro Mundo. Essa concepção contribui basicamente para formação da opinião pública acerca da importância das iniciativas internacionais no campo da saúde, mobilizando recursos financeiros e tecnológicos junto a agências internacionais bilaterais, tais como, Agência Americana para Desenvolvimento Internacional (USAID), Agência Canadense para o Desenvolvimento Internacional (CIDA). A atuação no campo da Saúde Internacional que prevalece nas ajudas bilaterais das agências de desenvolvimento e também na orientação de muitas universidades americanas, limita-se às iniciativas de países desenvolvidos direcionados para os pobres dos países subdesenvolvidos.

Muitos pesquisadores e consultores em desenvolvimento internacional trabalham nessa perspectiva, concebendo saúde internacional como prática unidirecional, onde os desenvolvidos ajudarão os pobres. Apesar de diferenças importantes entre os pesquisadores dessa corrente identifica-se que os mesmos observam o Terceiro Mundo numa perspectiva técnica proveniente de países mais avançados economicamente e tecnologicamente ${ }^{(1)}$.

A terceira corrente apresentada é o Funcionalismo ou

\section{Liberalismo Institucional.}

Os adeptos dessa corrente defendem que as atividades internacionais de saúde devem ser controladas e dirigidas, exclusivamente, por instituições internacionais contratadas, ou através de cartas assinadas por países membros, como resultado de acordos entre governo e instituições em diferentes países para controlar a doença ou promover a saúde.

Encontram-se nesse universo os defensores da Interdependência Internacional de Saúde Pública, dos Funcionalistas Ortodóxicos, dos Neofuncionalistas, e os defensores da Globalização. A corrente Funcionalista, ou do Liberalismo Institucional defende a liderança das organizações e acordos internacionais nas questões de Saúde Internacional, numa visão onde os problemas técnicos são mais relevantes que os problemas políticos.

Como exemplo desta corrente funcionalista tem-se a Organização Mundial da Saúde (OMS). Coloca-se como na condição de agência líder qualificada para atuar como um board of management dos problemas de Saúde Internacional, sendo que em alguns países, seus escritórios atuam como superministros da saúde.

Por último, a quarta corrente compreende a Saúde

\section{Internacional como Parte Das Relações Internacionais.}

Nesse universo identificamos cinco abordagens de Saúde Internacional, as quais algumas serão abordadas nesse estudo. São elas: Geomedicina, o Imperialismo e Saúde Internacional, a Teoria de Sistemas Mundial, a Diplomacia Médica e a Política de Saúde Internacional.

A Geomedicina surge na Alemanha anterior à 1930 resultante da combinação de geopolítica e práticas de saúde internacional. Foi utilizada por Hitler, durante a Segunda Guerra Mundial, dentro do princípio que define que a saúde deve estar de acordo com os interesses do Estado. Garrison, descreveu a Geomedicina como a nova ciência de gestão, que apresenta a cartografia de doenças sobre a terra, e das doenças sobre a civilização e vice versa. Sugere interrelação entre geopolítica e saúde e os impactos de saúde na sociedade ${ }^{(1)}$. Constata-se que a Geomedicina foi originalmente abraçada por grupos para exercer a dominação mundial e não visando o melhoramento mundial de saúde. A Geomedicina refere-se mais a um movimento onde o culto do caráter precede a investigação científica.

A Diplomacia Médica, outra vertente nas abordagens no campo internacional, tem contribuído muito para definir as relações de saúde entre países que mantém diferenças substanciais no campo político e ideológico.

Três exemplos clássicos da iniciativa da diplomacia médica, citando dois casos nos Estados Unidos e um em Cuba. No primeiro caso, inicia-se a diplomacia médica entre os EUA e o México, os quais possuíam afinidades diplomáticas. Verifica-se essa relação através da intervenção da Fundação Rockefeller durante a campanha contra a febre amarela nos anos 20. Segundo a avaliação feita por 
esse trabalho, relata-se que o sucesso da mesma decorreu principalmente, do esforço diplomático empreendido, resultante da certeza de que a febre amarela não ultrapassaria as fronteiras dos Estados Unidos ${ }^{(1)}$.

A segunda experiência da diplomacia médica, foi a tentativa do presidente americano Jimmy Carter, em 1978, quando buscou coordenar as ações realizadas por agências americanas no campo da Saúde Internacional, propondo que a coordenação e divulgação dos relatórios dessas atividades fossem realizadas pelos agentes governamentais da Casa Branca. 0 conhecimento e a coordenação das ações desenvolvidas possibilitaria a utilização dessas informações por outras áreas, tais como comércio e negócios. 0 estudo realizado nesse período, indicava oportunidades comerciais para os produtos relacionados com a saúde, e os possíveis serviços que poderiam ser atraídos através de programas assistenciais tradicionais ${ }^{(1)}$.

Essa visão, para além de ter uma proposta humanitária, traz no seu seio a preocupação com a possível contaminação do país central, por problemas advindos dos países subdesenvolvidos, uma vez que os Estados Unidos da América mantém relações econômicas e políticas com todos os países do globo, com exceção de Cuba.

\section{REFERÊNCIAS BIBLIOGRÁFICAS}

1. Panisset U. International health statecraf: the case of Peru's 1991 epidemic. [dissertation]. Baltimore (ML): University of Maryland;1996.

2. Castello RC. Áreas de fronteira: territórios de integração, espaços culturalmente identificados?. In: Castello IR, organizador. Práticas de integração nas fronteiras: temas para o Mercosul. Porto Alegre: Editora da UFRGS; 1995. p.15-26.

3. Carvalheiro JR. A saúde e o Mercosul. Série Assuntos Internacionais. Coleção documentos Instituto de Estudos Avançados 1992.
0 terceiro momento de cooperação diplomática em saúde dá-se em Cuba. Esse país acumulou capital simbólico para promover os cuidados de saúde junto a sua população; entretanto necessitou e ainda necessita de suporte e reconhecimento da opinião pública internacional para suas iniciativas. A diplomacia em Saúde Internacional de Cuba tem influenciado as agências internacionais de saúde e, especialmente, os sistemas de saúde dos países do Terceiro Mundo. Essa prática da diplomacia de saúde em Cuba aponta para quatro características, a saber: 0 alto nível das decisões tomadas, a participação da política cubana no processo, a inteligência em saúde e planejamento estratégico e os efeitos percebidos em outras áreas econômicas, tais como turismo e saúde dos trabalhadores, os quais têm implicações para o desenvolvimento da diplomacia em saúde internacional.

As abordagens contemporâneas de Saúde Internacional suscitam o apontamento de questões que merecem ser refletidas e discutidas nas diferentes instâncias de tomada de decisão dos países que compõem o bloco do Cone Sul para o desenvolvimento da política de Saúde Internacional na América Latina.

4. Ciccolella JP. Desconstrução/reconstrução do território no âmbito dos processos de globalização e integração. In: Santos M, Souza MA, Silveira ML. Território. Globalização e fragmentação. São Paulo: Hucitec; 1996. p. 296-307.

5. Schãeffer NO. Globalização e fronteira. In: Castello IR, Costa H, Hansen I, Lehnen AC, Schãeffer NO, Silva $P$ et al. Práticas de integração nas fronteiras: temas para o Mercosul. Porto Alegre (RS): UFRGS; 1995. p.70-91.

6. Rubarth EO. A diplomacia brasileira e os temas sociais: o caso da saúde. Brasília: Instituto Rio Branco; 1999.

7. Rosen G. Uma história de Saúde Pública. São Paulo: Hucitec; 1994. 8. Organización Panamericana de la Salud. (US). Pro salute Novo Mundi: historia de la Organización Panamericana de la Salud. Washington (DC): OPAS; 1992. 